\title{
Non-Traumatic Intracranial Heterotopic Ossification: A Case from Turkey
}

\author{
Mehmet Hanifi Kokacya1 ${ }^{*}$, Hasan Gökçe², Zeynel Abidin Taş3, Dua Sümeyra Demirkıran4, \\ Muhammet Mustafa Arslan ${ }^{4}$ \\ ${ }^{1}$ Department of Psychiatry, Faculty of Medicine, Mustafa Kemal University, Hatay, Turkey \\ ${ }^{2}$ Department of Pathology, Faculty of Medicine, İnonü University, Malatya, Turkey \\ ${ }^{3}$ Department of Pathology, Faculty of Medicine, Mustafa Kemal University, Hatay, Turkey \\ ${ }^{4}$ Department of Forensic Medicine, Faculty of Medicine, Mustafa Kemal University, Hatay, Turkey \\ Email: *mhkokacya@mku.edu.tr
}

Received 20 November 2015; accepted 4 January 2016; published 7 January 2016

Copyright (C) 2016 by authors and Scientific Research Publishing Inc.

This work is licensed under the Creative Commons Attribution International License (CC BY).

http://creativecommons.org/licenses/by/4.0/

c) (i) Open Access

\begin{abstract}
Heterotopic ossification (HO) is the abnormal, non-neoplastic presence of lamellar bone in soft tissue. The ectopic formation of lamellar bone in non-osseus tissues secondary to traumatic injuries of the spinal cord or the brain is defined as Neurogenic HO. The pathophysiology of HO is not clear. But several theories like overactive humoral mechanisms after fracture healing, imbalance of pro-osteoinductive and anti-osteoinductive mediators located on the soft tissues and gene mutations in such as bone morphogenetic proteins-4 (BMP-4) are proposed. Casualty factors leading to increased risk of $\mathrm{HO}$ include older age, blast mechanism of injury, location of injury and traumatic brain injury. The aim of this paper is to demonstrate a case of HO located in the brain without history of trauma or any other risk factors.
\end{abstract}

\section{Keywords}

Heterotopic Ossification, Autopsy, Traumatic Brain Injury

\section{Introduction}

Heterotopic ossification (HO) is defined as the abnormal formation of mature bone in soft tissue. It sometimes appears after direct trauma to muscles, large burns, fractures of long bones, and arthroplasty operations. As a result of proliferations of bone cells, a mature bone is formed in the muscle tissue, which is different from calcifications of the soft tissue involving calcium deposition [1]. HO was first described by Dejerne and Ceillier after

${ }^{*}$ Corresponding author.

How to cite this paper: Kokacya, M.H., Gökçe, H., Taş, Z.A., Demirkıran, D.S. and Arslan, M.M. (2016) Non-Traumatic Intracranial Heterotopic Ossification: A Case from Turkey. Forensic Medicine and Anatomy Research, 4, 17-21.

http://dx.doi.org/10.4236/fmar.2016.41003 
neurological injury in 1918, in soldiers with spinal cord injuries during World War I [2]. Neurogenic heterotopic ossification (HO) is a complication occurring after cranial and spinal cord injuries.

The incidence of $\mathrm{HO}$ due to increased osteoblasts and growth factors in the circulation following head trauma is also high [3]. It can be categorized as congenital or acquired; acquired HO is usually associated with trauma [4]. It has been reported that surgery on the same side of the hip as HO or contralateral side, prior surgery or trauma, ankylosing spondylitis, diffuse idiopathic skeletal hyperostosis, hypertrophic osteoarthritis, Paget's disease, posttraumatic arthritis, osteonecrosis and rheumatoid arthritis plays a role [5]. The etiology is not clearly known. There are many hypotheses about the pathophysiology of HO; to summarize, there is an interaction of local and systemic factors on mesenchymal stem cells resulting in their differentiation into osteoblasts and the formation of heterotopic ossification [6].

This report presents a case of neurogenic HO located in the falxcerebri without a history of trauma or any other risk factors.

\section{Case}

A 37-year-old male who died after his third suicide attempt by taking drugs was referred for autopsy. After taking 72 tablets of Seroquel (Quetiapine) $100 \mathrm{mg}$, he went to the police station and reported that he took sleeping pills to commit suicide. When he was taken to hospital, his Glasgow score was 8 and gastric lavage revealed drug particles. His condition deteriorated shortly after his admission, and he died. On forensic examination, he did not have traumatic lesions except for old, widespread, self-mutilative scars on both of his upper extremities and scar tissue, $4 \times 3 \mathrm{~cm}$ in size, on his left shoulder. The autopsy revealed hard calcified tissue, $4 \times 1 \times 0.3 \mathrm{~cm}$ in size, located below the dura mater freely between the two frontal lobes and independent of the arachnoidal membrane (Figure 1). There were no pathological features excluding edema and hyperemia in the brain tissue or the internal organs. Histopathological sections obtained after detection of hard, calcified tissue, decalcification, and other routine pathological examinations demonstrated heterotopic bone formation involving mature lamellar bone tissue and mature fat tissue in the intratrabecular space (Figure 2). Histopathological examination of the brain tissue revealed no abnormality.

The father's history showed that he had difficulty understanding and learning in his primary school and graduated from elementary school with a moderate degree. He worked with his father as an assistant in a car repair company, frequently had arguments with the other assistants there, and swore at everyone when he got angry. He was a smoker, rarely drank alcohol, and had difficulty sleeping. He was taking Quetiapine $100 \mathrm{mg} /$ day, prescribed

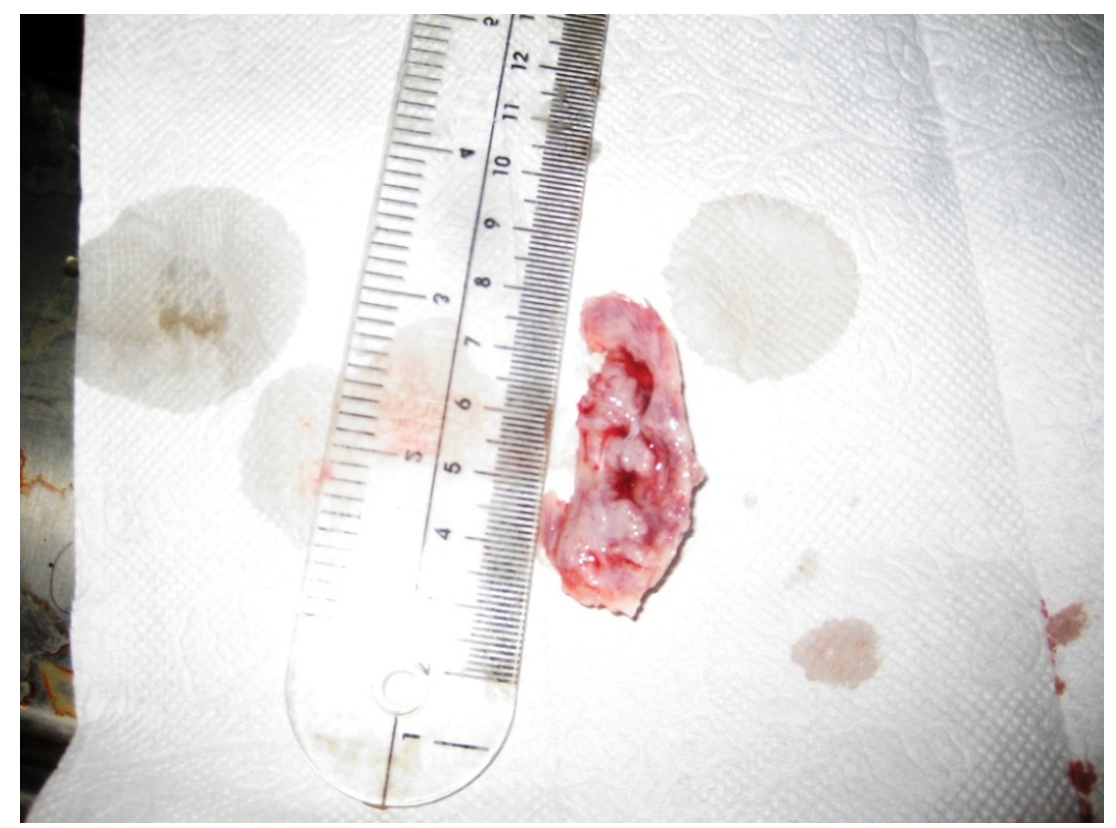

Figure 1. Calcified tissue $4 \times 1 \times 0.3 \mathrm{~cm}$ in size which was located below the dura mater freely between the two frontal lobes. 
by a psychiatrist for his insomnia. He was divorced once, married again, and had one child. He was sent to prison for smuggling. He reportedly had no physical trauma or significant diseases since his childhood.

Medical records revealed that he had attempted suicide twice by taking drugs; the first attempt was four years ago and the second was two months ago. He received treatment for infertility due to azoospermia. His biochemical tests and calcium levels were normal. Brain-computed tomography obtained after his last suicide attempt (two months previously) had demonstrated hyperdensity in the interhemispheric area in the frontal region, which suggested calcification (Figure 3).

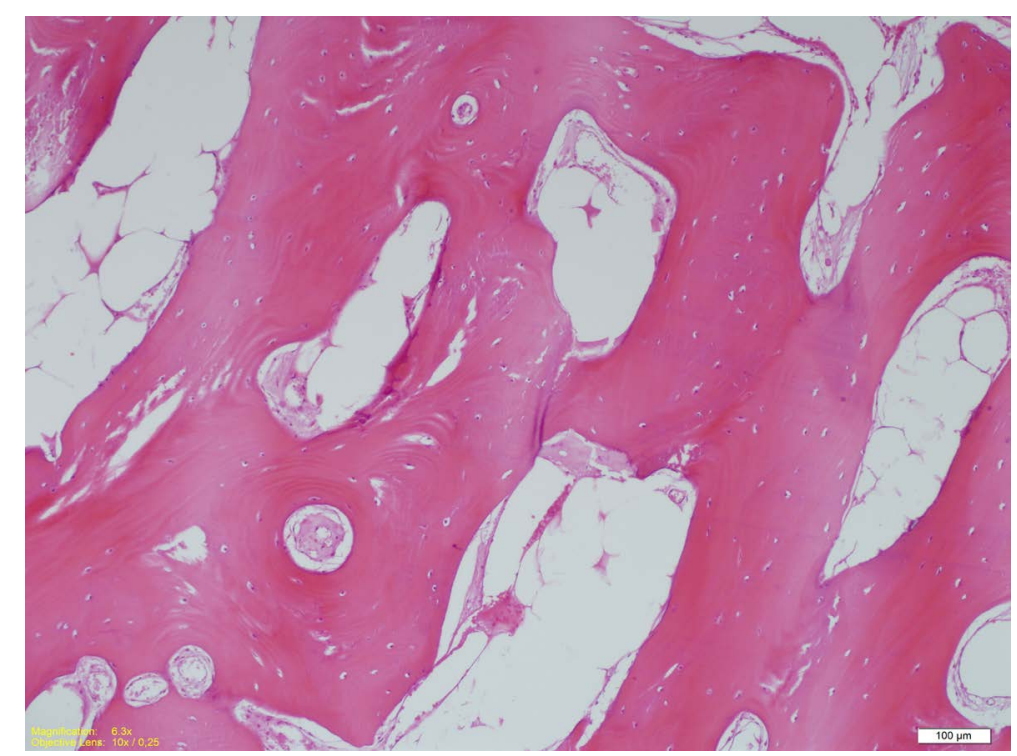

Figure 2. Histopathologicalsections heterotopic bone formation involving mature lamellar bone tissue and mature fat tissue in the intratrabecular space (H\&E, $\times 100)$.

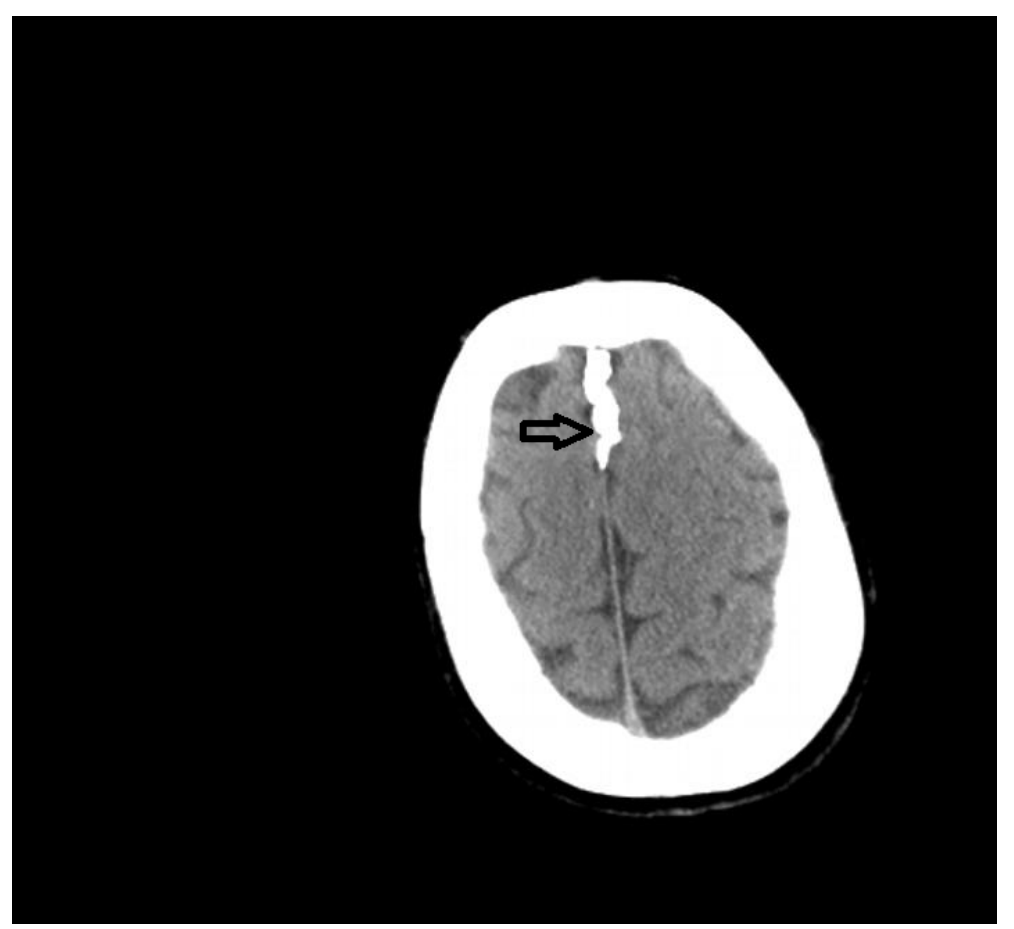

Figure 3. The axial brain CT image shows the heterotopic ossification (arrow). 


\section{Discussion}

Neurogenic HO is the ectopic formation of lamellar bone in non-osseus tissues secondary to traumatic injuries of the spinal cord or the brain. It reportedly occurred mostly below the injured area. The risk of HO in the muscles close to the joints increases after head trauma [4]. It has been reported that HO appears as a complication of direct trauma, especially in young people participating in sports, and almost all studies have shown that it occurs in muscles [1] [7]. The case presented here is interesting because medical history did not reveal trauma or cerebrovascular disease, and because the $\mathrm{HO}$ was located in the falxcerebri.

The pathophysiology of neurogenic $\mathrm{HO}$ is not clear. Histologically, $\mathrm{HO}$ is characterized by local microvascular changes and vascular stasis with encircled edema and swelling. Fibroblast and osteoblast proliferation, osteoid formation, and ectopic bone deposition are then formed [8]. It is hypothesized in several studies, that humoral mechanisms are active in accelerated fracture healing with increased bone formation after Traumatic Brain Injury (TBI) [3]. According to Chalmen's theory, formation neurogenic HO results from muscle progenitor cells, which are caused by mitogenic and osteogenic effects of the serum of central nervous system in injured patients. In other words, it is postulated that there is an imbalance of pro-osteoinductive and anti-osteoinductive mediators located in the soft tissues [9]. Another theory is that cell-mediated interactions with the local tissue environment (which are affected by $\mathrm{pH}$, oxygen amount, availability of micronutrients, and mechanic stimuli) lead to conversion of progenitor precursor cells to osteogenic precursor cells, and, as a result, HO occurs [10].

Another factor in the formation of HO is miyositisossificans (MO) progressiva. This is an autosomal-dominant disease characterized by Noggin gene mutation and excessive production of BMP-4. Although it most frequently occurs in the anterior and posterior parts of the thigh and the calf, it can display a progressive feature in the breasts, the tendons, the ligaments, and the striated muscles [11]. It more frequently appears in the second and third decades of life, especially in young, athletic, adult males [11] [12]. Gene mutations and BMP-4 were not investigated in the case presented here. However, it is interesting that there are not clinical features of MO disease, and the location of $\mathrm{HO}$ is different from the ones reported so far. The patient was working as a mechanic. When considering that his job required him to use his muscles, it becomes clear that he does not have any complaints due to MO.

Casualty factors leading to an increased risk of HO include age, the blast mechanism of the injury, the location of the injury and subsequent amputation, an injury severity score of $>16$, topical negative pressure dressings, traumatic brain injury, multiple extremity injuries, and the number of debridements before closure [13]. In the case presented here, no risks were reported in the literature for formation of $\mathrm{HO}$, which also makes it different from the similar cases presented up until now.

There is only one case of intracranial HO that does not involve a history of trauma or other provoking factors in the literature. The patient was reported to present with tingling and numbness in her arms, hip, and foot. On radiographic examinations, she had multiple $\mathrm{HO}$ formations in the right brain hemisphere and the falxcerebri. The HO was due to a childhood trauma, the cause of which was not reported [14]. The case presented here is different in terms of gender, size of $\mathrm{HO}$, and neurological signs. The patient in this case was male, had larger HO, and did not have neurological signs. A review of the patient's health records revealed no history of any past trauma. However, it is possible there was a minor head trauma that was not recorded or remembered.

It is notable that the patient had two prior suicide attempts because it is not known whether they were due to uncontrollable motives or depressive mood. However, a history obtained from his family showed that he did not have a depressive mood, had a good appetite, fulfilled his daily life activities, and went to the police station after taking drugs to commit suicide. All these findings in the patient's history rule out major depression. The suicide attempt could be in response to an event causing anger rather than a planned suicide. In fact, his father commented that the son got angry easily, lost control, and became furious. Because insomnia and irritability were seen in the patient, manic depressive disorder was suspected. However, the patient had no history of a manic episode. Euphoria, increased energy, libido and talking speed, disconnected racing thoughts, grandiose beliefs, hallucinations, or delusionals were not observed by his family or peers. Most important, his irritability was not episodic. Because it is essential to have at least one manic episode for the diagnosis of manic depressive disorder, the case was not diagnosed as such.

Lack of TBI or trauma history, normal findings on cranial CT, and lack of sudden mood changes rule out frontal lobe syndrome. The distinctive feature of this case is that he had neurogenic HO without any trauma to the brain or the spinal cord. HO was accompanied by failure at school, disruptive behavior, sleep problems, and 
infertility. Despite their unknown etiology, the patient's personality and sleep problems, which accompanied the $\mathrm{HO}$, were interesting.

\section{Conclusion}

It should be noted that patients who easily anger and experience behavior problems may have HO in the brain. Understanding the physiology of non-traumatic heterotopic ossification will enable the physician to treat the pathologic process more effectively.

\section{Conflict of Interest}

There are no conflicts of interest in connection with this paper and there is no funding for this research.

\section{References}

[1] Pittenger, D.E. (1991) Heterotopic Ossification. Orthopaedic Review, 20, 33-39.

[2] Citta-Pietrolungo, T.J., Alexander, M.A. and Steg, N.L. (1992) Early Detection of Heterotopic Ossification in Young Patients with Traumatic Brain Injury. Archives of Physical Medicine and Rehabilitation, 73, 258-262.

[3] Garland, D.E. (1991) A Clinical Perspective on Common Forms of Acquired Heterotopic Ossification. Clinical Orthopaedics and Related Research, 263, 13-29. http://dx.doi.org/10.1097/00003086-199102000-00003

[4] Bidner, S.M., Rubins, I.M., Desjardins, J.V., Zukor, D.J. and Goltzman, D. (1990) Evidence for a Humoral Mechanism for Enhanced Osteogenesis after Head Injury. Journal of Bone and Joint Surgery, 72, 1144-1149.

[5] Cipriano, C.A., Pill, S.G. and Keenan, M.A. (2009) Heterotopic Ossification Following Traumatic Brain Injury and Spinal Cord Injury. Journal of the American Academy of Orthopaedic Surgeons, 17, 689-697.

[6] Chao, S.T., Joyce, M.J. and Suh, J.H. (2007) Treatment of Heterotopic Ossification. Orthopedics, 30, 457-466.

[7] Sakellariou, V.I., Grigoriou, E., Mavrogenis, A.F., Soucacos, P.N. and Papagelopoulos, P.J. (2012) Heterotopic Ossification Following Traumatic Brain Injury and Spinal Cord Injury: Insight into the Etiology and Pathophysiology. Journal of Musculoskeletal \& Neuronal Interactions, 12, 230-240.

[8] Iorio, R. and Healy, W.L. (2002) Heterotopic Ossification after Hip and Knee Arthroplasty: Risk Factors, Prevention and Treatment. Journal of the American Academy of Orthopaedic Surgeons, 10, 409-416.

[9] Chalmers, J., Gray, D.H. and Rush, J. (1975) Observations on the Induction of Bone in Soft Tissues. Journal of Bone and Joint Surgery (British Volume), 57, 36-45.

[10] Ranganathan, K., Loder, S., Agarwal, S., Wong, V.C., Forsberg, J., Davis, T.A., et al. (2015) Heterotopic Ossification: Basic-Science Principles and Clinical Correlates. Journal of Bone and Joint Surgery (American Volume), 97, 11011111. http://dx.doi.org/10.2106/JBJS.N.01056

[11] Parikh, J., Hyare, H. and Saifuddin, A. (2002) The Imaging Features of Post-Traumatic Myositis Ossificans, with Emphasis on MRI. Clinical Radiology, 57, 1058-1066. http://dx.doi.org/10.1053/crad.2002.1120

[12] Hanquinet, S., Ngo, L., Anooshiravani, M., Garcia, J. and Bugmann, P. (1999) Magnetic Resonance Imaging Helps in the Early Diagnosis of Myositis Ossificans in Children. Pediatric Surgery International, 15, 287-289. http://dx.doi.org/10.1007/s003830050580

[13] Edwards, D.S. and Clasper, J.C. (2014) Heterotopic Ossification: A Systematic Review. Journal of the Royal Army Medical Corps, 161, 315-321. http://dx.doi.org/10.1136/jramc-2014-000277

[14] Gribsholt, S.B., Stochholm, K., Mosekilde, L. and Vestergaard, P. (2014) Heterotopic Ossification in the Brain Can Occur without Preceding Trauma. Ugeskr Laeger, 176, 1411-1412. 